\title{
The mechanical behaviours of the Ti-10V-2Fe-3Al alloy under the high-temperature and dynamic loading conditions
}

\author{
Lintao $\mathrm{Li}^{1,2}$, Xiaoying Zhang ${ }^{1,2}$, Zhiqiang $\mathrm{Li}^{2}$, Zhihua Wang ${ }^{2}$ and Wei $\mathrm{Ma}^{1 *}$ \\ ${ }^{1}$ Institute of Mechanics, Chinese Academy of Sciences, Beijing 100190, China \\ ${ }^{2}$ Institute of Applied Mechanics and Biomedical Engineering, Taiyuan University of Technology, Taiyuan 030024, China
}

\begin{abstract}
In this work, we develop a high-temperature dynamic testing technology for characterizing the properties of Ti-1023 alloy. The modified Hopkinson torsion bar system includes a high-temperature furnace subsystem and a water cooling subsystem. High-temperature dynamic tests of the alloy are performed. The dependence of the yield stress on the temperature and the shear strain rate is studied. The scanning electron microscopy observations show that the microstructural evolution makes up of two steps: the first one is caused by thermal loading and the second one by the mechanical loading. The hightemperature dynamic constitutive model is established based on the experimental results.
\end{abstract}

\section{Introduction}

Titanium Ti-1023 alloy is used to produce key components of aviation engine in the aerospace industry due to its high specific strength and stiffness. Its mechanical behaviour has been extensively studied for understanding the deformation mechanism and the influence of phase stability on the plastic flow process under isothermal compression and tension loading conditions [1-2]. So far, many metallurgical characteristics on microscale, such as the transformationinduced orthorhombic structure, the martensitic and twinning transformation, and the fragmentation and spheroidization of phase at low strain rate and below $\beta$ transition temperature, have been studied [3-6]. Moreover, in the room-temperature environment and lowstrain rate loading, the influences of applied loading and plastic deformation on the martensitic and twinning transformation has been studied [6-9]. However, a few of studies of the mechanical behaviour under the hightemperature environment and high-strain rate loading conditions has been conducted. Owing to the difficult-tocut characteristic, Titanium alloy makes the machining processing face a hard situation [10-13]. In the machining process, the strong shear deformation of work-material and the friction between tool and chip generate lots of heat. For better understanding the machinability of this alloy, it is necessary to intensive study the mechanical behaviours under the high-temperature and high-strain rate shear loading conditions. This is our main concern at present.

In this article, we improved the original design of Hopkinson torsion bar device to develop a hightemperature loading system for characterizing high-rate properties of the Ti-10V-2Fe-3Al alloy at elevated temperature. The modified Hopkinson bar system includes a high-temperature furnace subsystem and a water cooling subsystem with two cooling cavities. Hightemperature dynamic torsion tests of the Ti-1023 alloy are performed. The dependence of the yield stress on the temperature and the shear strain rate is determined. The post scanning electron microscopy observes that the microstructural evolution makes up of two steps: the first one is caused by thermal loading and the second one by the mechanical loading. The high-temperature dynamic constitutive model is established based on the experimental results.

\section{Experiment}

The testing apparatus used in this study is shown in Fig. 1. This apparatus consists of a SHTB system for applying the dynamic torsion loading on the specimen, a heater system for producing high-temperature testing environment for the specimen and a water cooling system for maintaining the room temperature for the strain gauges. The measuring devices include a strain gauge system for measuring the strain voltages of SHTBs and a temperature measuring system composed of a pair of thermocouples. Thea high-temperature furnace subsystem can create an elevated temperature environment for the testing specimen in the range of $20{ }^{\circ} \mathrm{C}$ to $1100{ }^{\circ} \mathrm{C}$. The water cooling subsystem with two cooling cavities installs separately the joints between the sample and the incident and transmission bars. In the heating process, the high pressure water flow prevents the heat diffusion along these bars and makes sure that the connectors between the specimen and these Hopkinson bars are in the roomtemperature environment. Thus, the strain gauges always operate at room temperature environment, resulting in the reliability and accuracy of the measured data. Like the SHPB apparatus, the principle of the SHTB apparatus is based on one-dimensional stress wave theory. 
The specimen used in this study is shown in Fig. 1. The specimen dimensions are $180 \mathrm{~mm}$ in length, $25 \mathrm{~mm}$ in outer diameter and $15 \mathrm{~mm}$ in inner diameter. In order to make the specimen be evenly heated in experiment, the testing section of specimen is prepared as thin wall cylinder with the dimensions: external diameter $15 \mathrm{~mm}$, wall thickness $0.5 \mathrm{~mm}$ and high $2 \mathrm{~mm}$. The thermocouple device is used to monitor the testing temperatures of the outer and inner walls of sample simultaneously. Presently, application of a long specimen is to facilitate the installation of water cooling system in testing process.

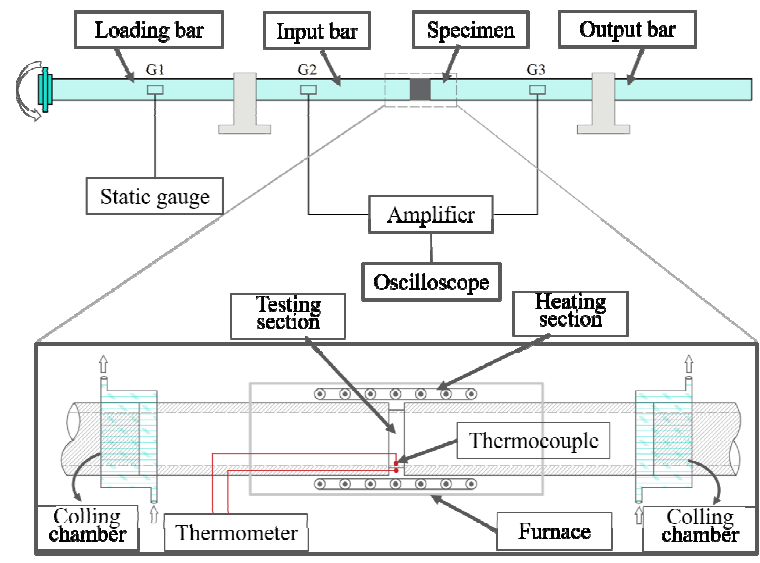

Fig.1. Schematic diagram of the high-temperature torsion SHPB apparatus with assistant water cooling system.

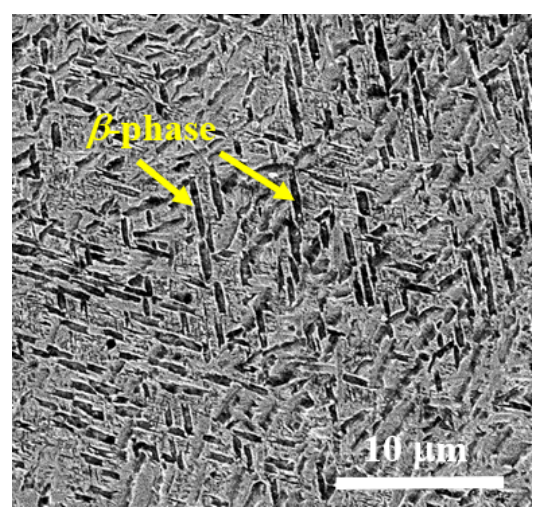

Fig. 2. Initial duplex $\alpha+\beta$ microstructure of as received Ti-1023 alloy specimens in transverse cross-section, where $\beta$-phase is dark as demonstrated by the yellow arrows and $\alpha$-phase is bright.

The Ti-1023 alloy is selected as testing material in this study. The content of alloying elements (wt. \%) is: $84 \mathrm{Ti}$, $10.5 \mathrm{~V}, 3.15 \mathrm{Al}, 2.1 \mathrm{Fe}, 0.02 \mathrm{C}, 0.01 \mathrm{O}, 0.03 \mathrm{~N}, 0.002 \mathrm{H}$. The initial yield strength and tension strength are $1035 \mathrm{MPa}$ and $1105 \mathrm{MPa}$, respectively. The melting point is $1668^{\circ} \mathrm{C}$ [14]. The primary microstructure of the alloy is shown in Fig. 2. The observation reveals that this alloy contained coarse non-equiaxed $\beta$-phase grains which precipitated in the $\alpha$-phase matrix to yield a structure of high strength. The average $\beta$-phase grain size is approximately 3-7 $\mu \mathrm{m}$ in length and $2 \mu \mathrm{m}$ in width. In the near- $\beta$ Ti-1023 alloy, the $\beta$-phase with bcc structure has a proportion of 40 -
$50 \%$ and remains steady state from $20{ }^{\circ} \mathrm{C}$ to the $\beta$-phase transus temperature of $780-800{ }^{\circ} \mathrm{C}[14,15]$.

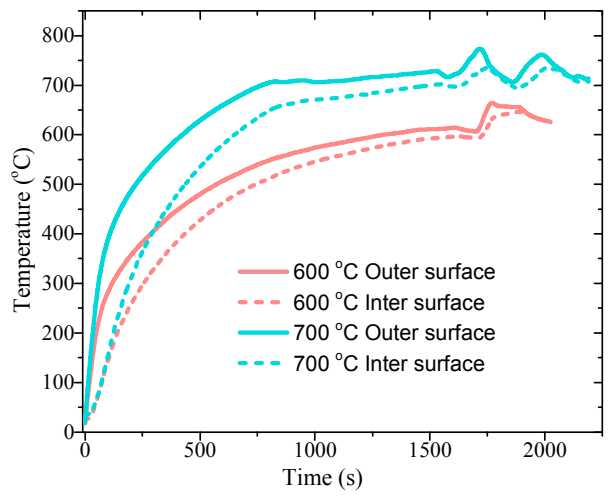

Fig. 3. The measured temperature-time curves.

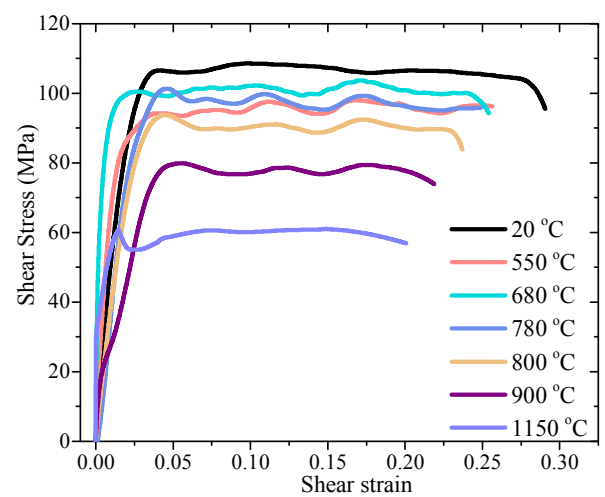

Fig. 4. The shear stress-strain curves in the range of temperature of $20{ }^{\circ} \mathrm{C}$ to $1150{ }^{\circ} \mathrm{C}$ and at constant strain rates of $1230 \mathrm{~s}^{-1}$.

A uniform temperature distribution over the entire specimen is required in this high-temperature experiment. A heating source of resistance wire is used to heat the specimen for measuring the high-temperature flow stresses and strains of material. The highest temperature of the resistance wire itself can reach $1500{ }^{\circ} \mathrm{C}$, which makes it possible heat the specimen in the wide range from $20-1100{ }^{\circ} \mathrm{C}$. During testing, the temperatures on the specimen inner and outer walls were simultaneously measured by using the contact thermocouple technology (Fig. 1) and the measured temperature-time curves are shown in Fig. 3. When the specimen is heated up to the testing temperature designated, the two sets of data can be increased synchronously and the maximum difference is less than the $10 \%$. The difference between the inner and outer wall temperature depends on heating rate. When the heating rate is lower, the difference can reduce evidently.

\section{Results and discussion}

The shear stress-strain curves in the range of temperature of 20 to $1150{ }^{\circ} \mathrm{C}$ at constant strain rates of $1230 \mathrm{~s}^{-1}$ are shown in Fig. 4. All these curves exhibited an initial strain hardening behavior in the range of small strain. After that, a steady state flow behavior is observed at the constant strain rate and the testing temperature environment. The influence of testing temperature on the 
flow stresses is evident. When the testing temperature is lower than the $\beta$-phase transus temperature of the alloy $\left(780-800{ }^{\circ} \mathrm{C}\right)$, the flow stress intensity decreases slightly comparing with that of original alloy and is almost independent on the variation of testing temperature. When the temperature is higher than the $\beta$-phase transus, the flow stresses are strongly dependent on the testing temperatures and the flow stress intensity decreases sharply. The discontinuous variation of flow stresses in intensity was reported [16] due to the generation of dislocation from grain boundary sources. The hightemperature plastic deformation starts from the grain boundary and spreads inwards the interior of the crystal structures. The flow stress decrease depends on the strain rate, temperature and content of $\beta$-phase stabilizers [16, 17]. It was also observed in Ti6Al4V alloy and other Titanium alloys [16-18].

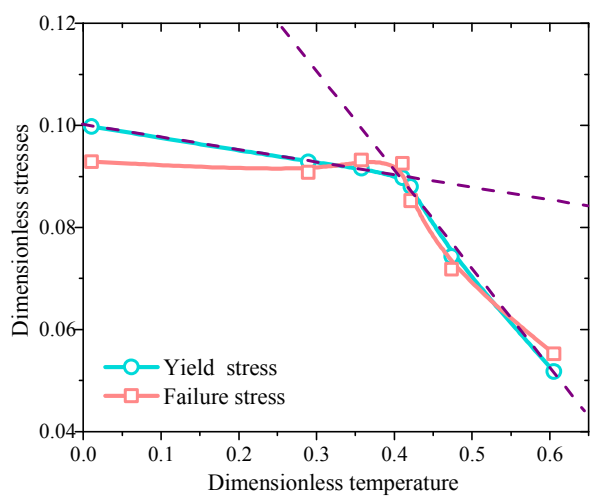

Fig. 5. Variations of the yield and failure stresses with the testing temperature at constant strain rates of $1230 \mathrm{~s}^{-1}$.

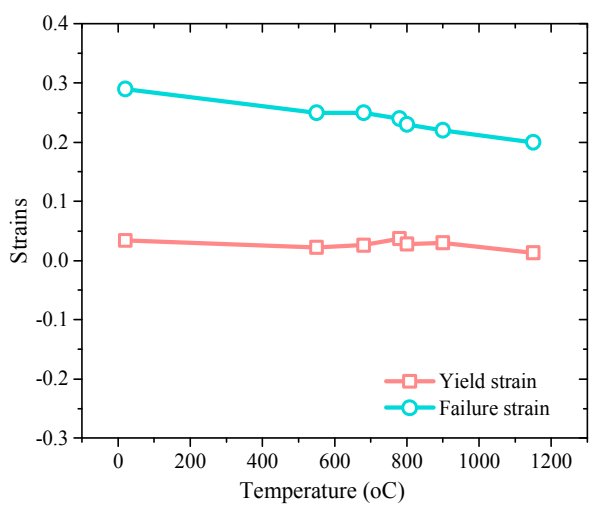

Fig. 6. Variations of the yield and failure strains with the testing temperature at constant strain rates of $1230 \mathrm{~s}^{-1}$.

In Fig. 5, the dependences of the yield stresses and the failure stresses on the testing temperature are shown. These stresses are less than the initial values slightly and have higher intensity as the temperature is lower the $\beta$ phase transus, and they are sharply decrease as the temperature is higher than the $\beta$-phase transus. However, the yield strain and the failure strain are almost not related to the testing temperature as shown in Fig. 6

The microstructural changes of the specimens at 550, 780 , and $900{ }^{\circ} \mathrm{C}$ and at the strain rate of $1230 \mathrm{~s}^{-1}$ are shown in Fig. 7 to Fig.9, respectively. In these figures, figure (a) shows the changes of microstructures only produced by the thermal loading and figure (b) shows those by the thermos-mechanical loading. We can see that the thermal loading, i.e. the environmental temperature rise is $550{ }^{\circ} \mathrm{C}$, firstly makes the concentration of $\beta$-phase raise slightly with an associated refinement in the $\beta$-phase grain (Fig. 7a). Then, when the specimen subjects to the mechanical loading at $550{ }^{\circ} \mathrm{C}$ again, the $\beta$-phase concentration remains unchanged besides a few of the $\beta$ phase grains spheroidize (Fig. 7b). Therefore, the intensity of flow stress doesn't decrease significantly. When the testing temperature rises to $780{ }^{\circ} \mathrm{C}$, both of the thermal loading and the thermo-mechanical loading don't induce the grain refinement in size and the concentration variation of $\beta$-phase (Fig. 8), which make the flow stresses recover in intensity so that the flow stress intensity closes to the intensity of original material at 20 ${ }^{\circ} \mathrm{C}$ (Fig. 4). When the testing temperature is beyond the $\beta$ phase transus temperature $780-800{ }^{\circ} \mathrm{C}$, such as reaching $900{ }^{\circ} \mathrm{C}$, the thermal loading prior to mechanical loading remarkably causes refinement and spheroidizes of the $\beta$ phase grains of alloy (Fig. 9a). The following mechanical loading further increases the equiaxed grain of $\beta$-phase in size (Fig. 9b). The increasing concentration of $\alpha$-phase (white portions) that precipitates dispersively around the $\beta$-phase grains generates a structure of low strength of alloy material. This change of the microstructure of alloy is main reason that results in the intensity decrease of flow stresses of alloy.
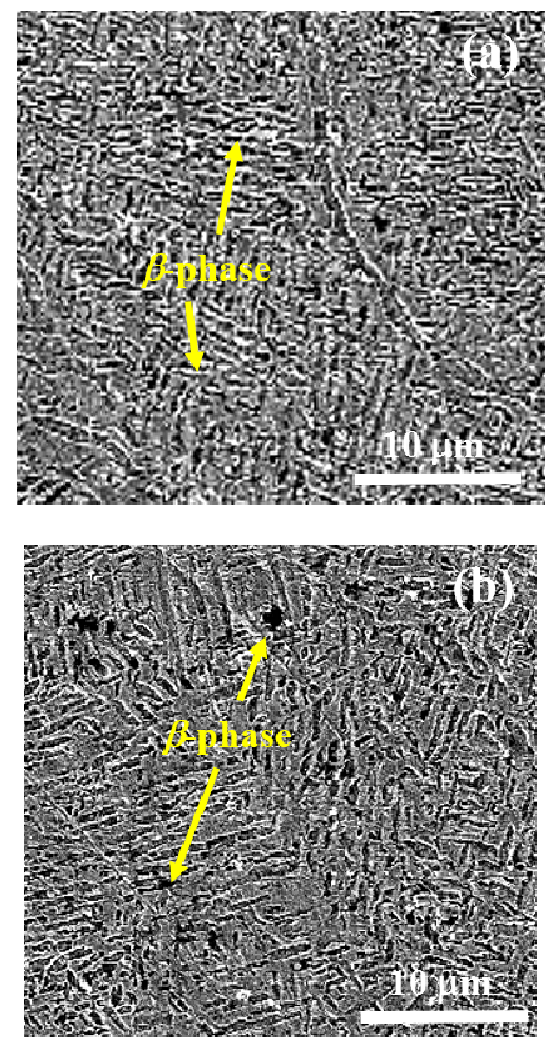

Fig. 7. Under the testing temperature condition of $550{ }^{\circ} \mathrm{C}$, the change of the Ti-1023 alloy microstructure is caused by the thermal loading (a) and the thermo-mechanical loading (b), respectively. 
The growth of $\alpha$-phase in concentration during shear plastic flow accounts for the shifting of the yield stress and flow stress of alloy to the low intensity due to thermal softening effect under the high temperature and the high strain conditions. This is related to the activation energy of alloy under the loading condition. The mechanism of shear plastic flow involves the sliding of grain boundaries and the stress concentration at the grain boundary triplejunction. In the high-temperature environment, the strain rate controls the plastic flow mechanism through the stress accommodation process. When the testing temperature is lower than the $\beta$-phase transus, the activation energy required for $\beta$-phase transition in the plastic flow of alloy is higher than the work done by the high-temperature dynamic loadings, the refinement and transition in $\beta$-phase grains are difficult in this case. The decrease of $\beta$-phase of alloy in concentration is not significant and the alloy intensity maintains the high level. When the testing temperature is higher than the $\beta$ phase transus, the work done by external loadings is larger than the activation energy for the $\beta$-phase transition in the high-temperature and high strain rate environment. It is possible that the strain rate controlling the shear plastic flow inhibits the dynamic recrystallization of $\beta$ phase and assists relatively fast refinement and transition of $\beta$-phase grain in bcc structures of near- $\beta$ Ti- 1023 alloy. This observation is in agreement with the hightemperature deformation behaviour of the alloy observed by Robertson and McShane [19].

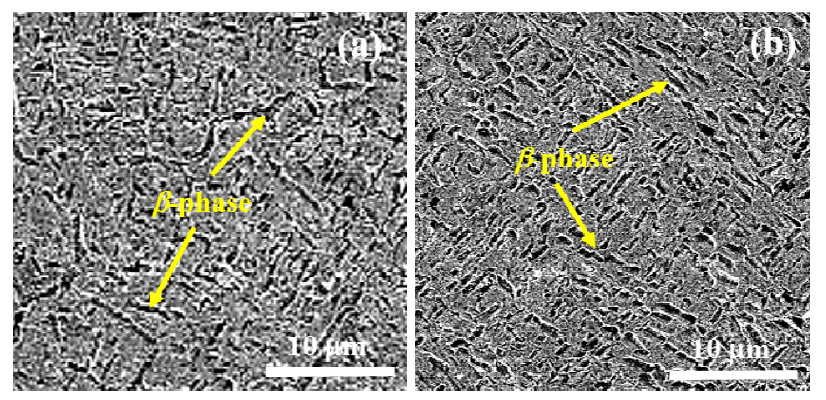

Fig. 8. Under the testing temperature condition of $780{ }^{\circ} \mathrm{C}$, the change of the Ti-1023 alloy microstructure is caused by the thermal loading (a) and the thermo-mechanical loading (b), respectively.
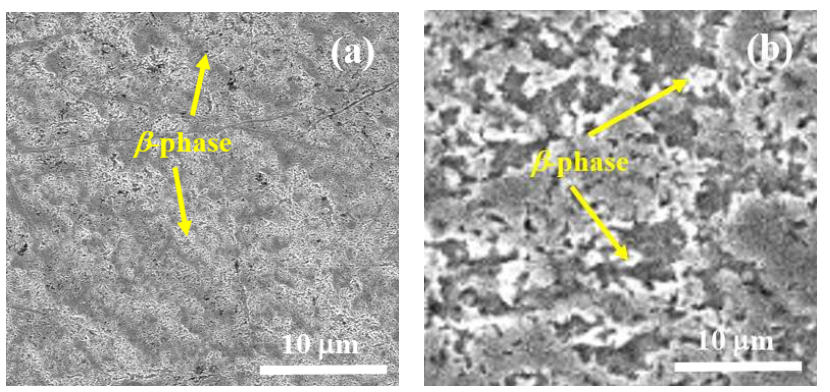

Fig. 9. Under the testing temperature condition of $900{ }^{\circ} \mathrm{C}$, the change of the Ti-1023 alloy microstructure is caused by the thermal loading (a) and the thermo-mechanical loading (b), respectively.

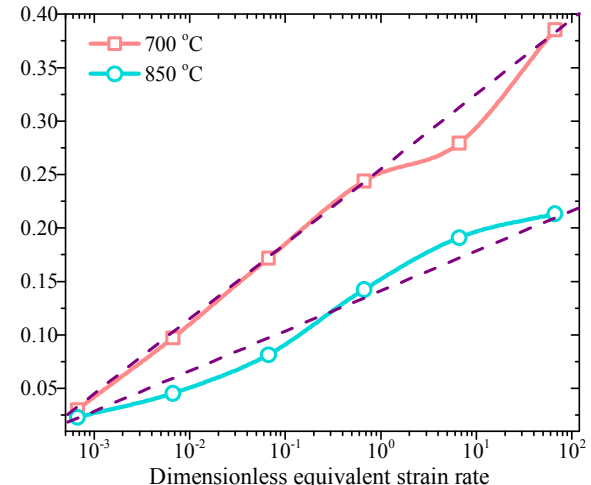

Fig. 10. The dependence of yield stresses in compression on the strain rate at various temperatures [20].

\section{Constitution model}

The experimental results show that the yield stress of Ti1023 alloy is dependent on the testing temperature (Fig. 5). The experimental study of compression carried out by Balasubrahmanyam and Prasad [20] shows that it is also sensitive to the strain rate (Fig. 10). As the strain rate is higher than $1.0 \mathrm{~s}^{-1}$, the alloy exhibits significant flow softening and the strain rate is lower, a steady plastic flow presents after an initial yield Fig. 11. These behaviours are representative of the mechanical properties of the alloy on both sides of the $\beta$-transus temperature. In terms of these observations, a modified Johnson-Cook constitutive model can be reasonably established for the alloy. The dimensionless $\mathrm{J}-\mathrm{C}$ constitutive law [21] is

$$
\hat{\sigma}_{e q}^{p}=\left[\hat{A}+\hat{B}\left(\hat{\varepsilon}_{e q}^{p}\right)^{n}\right]\left(1+C \ln \hat{\dot{\varepsilon}}_{e q}^{p}\right)\left(1-\hat{T}^{m}\right)
$$

where

$$
\hat{\sigma}_{e q}^{p}=\frac{\sigma_{e q}^{p}}{\sigma_{s}}, \hat{A}=\frac{A}{\sigma_{s}}, \hat{B}=\frac{B}{\sigma_{s}}, \hat{\dot{\varepsilon}}_{e q}^{p}=\frac{\dot{\varepsilon}_{e q}^{p}}{\dot{\varepsilon}_{0}}, \hat{T}=\frac{T-T_{0}}{T_{m}-T_{0}}
$$

are the equivalent plastic stress, initial yield stress, hardening module, equivalent plastic strain rate and the temperature in dimensionless form. $T_{0}, T_{m}$ and $\sigma_{s}$ are the room temperature, the melding point and the yield strength of Ti-1023 alloy, $\dot{\varepsilon}_{0}$ is the reference strain rate.

The hat ' $\wedge$ ' over a variable denotes that the variable is dimensionless. The 'dot' over a variable denotes the differentiation of time.

In the uniaxial compression case, the J-C law (1) becomes

$$
\hat{\sigma}=\left[\hat{A}+\hat{B}\left(\frac{2 \hat{\varepsilon}}{3}\right)^{n}\right]\left(1+C \ln \frac{2 \hat{\dot{\varepsilon}}_{e q}^{p}}{3}\right)\left(1-\hat{T}^{m}\right)
$$

and in the simple shear case,

$$
\hat{\tau}=\frac{1}{\sqrt{3}}\left[\hat{A}+\hat{B}\left(\frac{\hat{\gamma}}{\sqrt{3}}\right)^{n}\right]\left(1+C \ln \frac{\hat{\gamma}}{\sqrt{3}}\right)\left(1-\hat{T}^{m}\right)
$$

In (3) and (4), $\sigma, \varepsilon, \tau$ and $\gamma$ are the compressive stress and strain, and the shear stress and strain. The material parameters in the J-C law $\hat{A}, \hat{B}, C, m$ and $n$ will be determined in terms of the presently experimental result as shown in Fig. 5 and the results of reference [7] (Fig. 10). Consider the dependence of the compression yield stress on the equivalent strain rate, the slope $C$ of the 
strain rate term in (3) can be determined to be $C_{1}=5.3 \times 10^{-}$ ${ }^{3}$ as the temperature is lower than $\beta$-phase transus and $C_{2}=1.3 \times 10^{-3}$ as it is higher than $\beta$-phase transus.
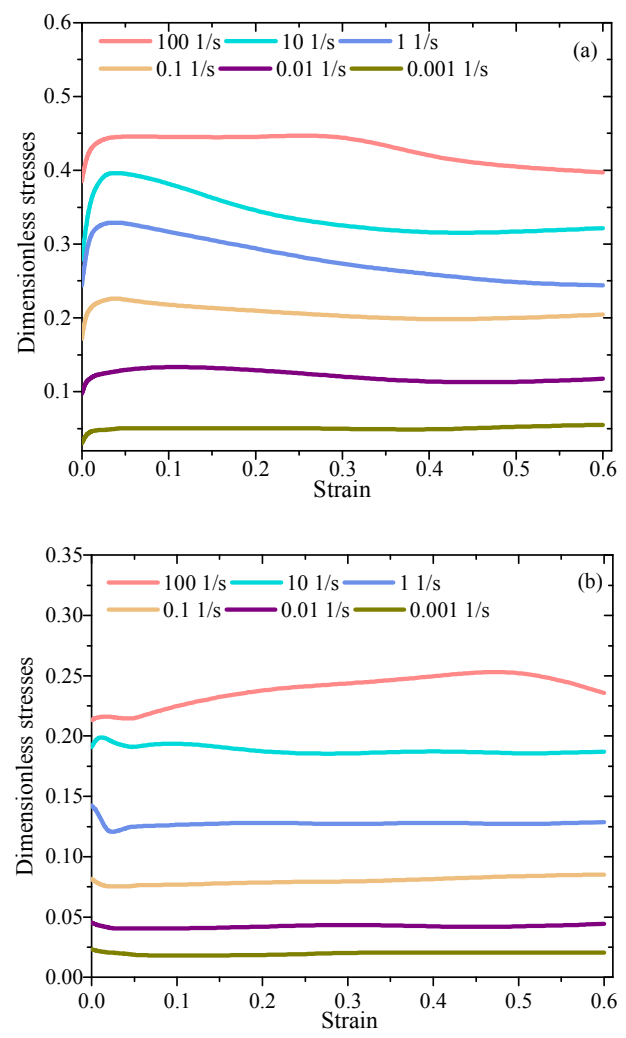

Fig. 11. The stress-strain curves obtained in the compression experiments with variable strain rates at given temperatures to be lower (a) and higher (b) than the $\beta$-phase transus for Ti-1023 alloy [20].

In terms of the experimental results of simple shear in Fig. 5, we may find the $m_{1}=2.5 \times 10^{-2}$ as the temperature is lower than $\beta$-phase transus and $m_{2}=1.95 \times 10^{-1}$ as it is higher than $\beta$-phase transus. Thus, the $\mathrm{J}-\mathrm{C}$ constitutive equations (1) can be rewritten as

$\hat{\sigma}_{e q}^{p}=\left[\hat{A}+\hat{B}\left(\hat{\varepsilon}_{e q}^{p}\right)^{n}\right]\left(1+C_{i} \ln \hat{\dot{\varepsilon}}_{e q}^{p}\right)\left[\left(2-m_{i}\right)-\hat{T}^{m_{i}}\right],(i=1,2)^{(5)}$

where $i=1,2$ corresponds to the testing temperature is lower and higher than the $\beta$-phase transus. The stressstrain relationships of Ti-1023 alloy in the cases of the simple shear (Fig. 5) and the uniaxial compression (Fig. 11) show that the plastic flow behaves strain hardening during the small strain deformation and the temperature is lower than the $\beta$-phase transus. When the temperature is higher than the $\beta$-phase transus, the strain hardening effect disappears. Thus, the strain hardening module $\hat{B}$ and the strain hardening exponential $n$ in (5) can be determined in terms of the experimental results as the temperature is lower than the $\beta$-phase transus. Fig. 12 shows the stress-strain curves of the alloy during the strain hardening deformation in the simple shear case (Fig. 12a) and the uniaxial compression case (Fig. 12b). In these figures, the nonlinear curve fit to these experimental results are provided. Based on these fitting results, the strain hardening module $\hat{B}_{1}$ can be determined in terms of the equivalent stress definition as follows

$$
\hat{B}_{1}=\sqrt{\hat{B}_{C}^{2}+3 \hat{B}_{S}^{2}}
$$

where $\hat{B}_{S}=0.49$ and $\hat{B}_{C}=0.31$ are the mean strain hardening modules in the simple shear case and the uniaxial compressive case, respectively. From the equation (6), the value of the mean equivalent strain hardening module is found as $\hat{B}_{1}=0.73$. The strain hardening exponential is found as $n=0.12$. Similarly, the equivalent initial yield stress $\hat{A}$ is determined as

$$
\hat{A}=\sqrt{\hat{A}_{C}^{2}+3 \hat{A}_{S}^{2}}
$$

where $\hat{A}_{C}$ and $\hat{A}_{S}$ are the initial yield stresses in the uniaxial compression and simple shear cases respectively. Their values can be obtained from the results of Fig. 10 and Fig. 5. The temperature-dependence of dimensionless initial yield strength and the hardening module is determined by the third term of the constitutive law (5).
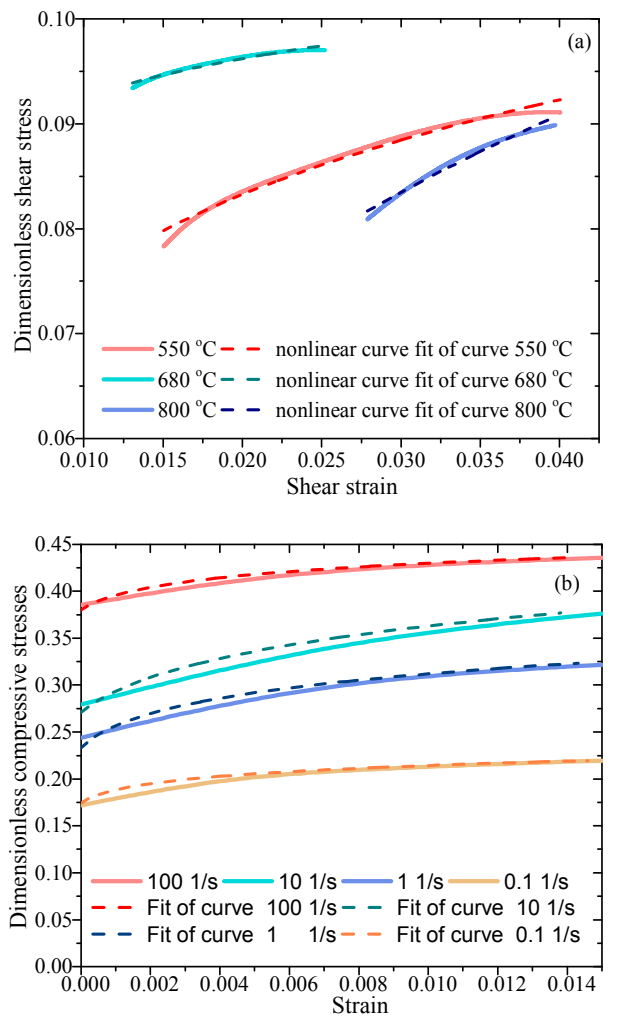

Fig.12. The stress-strain curves in the hardening stage obtained in the simple shear experiments (a) [present] and in the compression experiments (b) [7] as the testing temperatures is lower than the $\beta$-phase transus for Ti1023 alloy.

\section{Conclusion}

In this article, we develop a set of testing apparatus and corresponding high-temperature dynamic torsion experimental technology for the measuring the shear yield strength and flow stress of Ti-1023 alloy under the hightemperature and high-strain rate conditions. The 
microscopic experiment observations show that the microstructure of Ti-1023 alloy is sensitive to the external thermal loading. As the testing temperature is lower than the $\beta$-phase transus, the $\beta$-phase concentration almost remains unchanged besides a few of the refinement and spheroidize of $\beta$-phase grains, which results in the maintaining of high yield strength of alloy. When the testing temperature is higher the $\beta$-phase transus, the thermal loading and mechanical loading can respectively cause various refinement and spheroidize of the $\beta$-phase grain of alloy, which remarkably decrease the yield strength of alloy. On the basis of the resulting stress and strain data obtained in simple shear, the high-temperature

\section{References}

1. M. Ahmed, D. Wexler, et al. The influence of $b$ phase stability on deformation mode and compressive mechanical properties of Ti-10V-3Fe-3Al alloy. Acta Materialia 84 124-135 (2015)

2. D.G. Robertson, H.B. Mc Shane, Isothermal hot deformation behavior of metastable beta titanium alloy Ti-10V-2Fe-3Al, Mater. Sci. Technol. 13 575-583 (1999)

3. Suresh Neelakantan, P.E.J. Rivera-Diaz-del-Castillo and Sybrand van der Zwaag. Prediction of the martensite start temperature for $b$ titanium alloys as a function of composition. Scripta Materialia 60 611-614 (2009)

4. F. Warchomicka, M. Stockinger, H.P. Degischer. Quantitative analysis of the microstructure of near titanium alloy during compression tests. Journal of Materials Processing Technology 177 473-477 (2006)

5. M. Jackson, R. Dashwood, L. Christodoulou, H. Flower, Application of novel technique to examine thermomechanical processing of near $\beta$ alloy Ti-10V2Fe-3Al, Materials Science and Technology. 161437 (2000)

6. M. Jackson, R. Dashwood, L. Christodoulou, H. Flower, The microstructural evolution of near beta alloy Ti-10V-2Fe-3Al during subtransus forging, Metall. Mater. Trans. A 36A 1317-1327 (2005)

7. T.W. Duerig, J. Albrecht, D. Richter, P. Fischer. Formation and Reversion of Stress Induced Martensitic in Ti-10V-2Fe-3Al. Acta Metall. 30 2161-2172 (1982)

8. C. Li, J.H. Chen, et al., Tuning the stress induced martensitic formation in titanium alloys by alloy design. J. Mater. Sci. 47 4093-4100 (2012)

9. S.L. Semiatin, T.R. Bieler, The effect of alpha platelet thickness on plastic flow during hot working of Ti6Al4V with a transformed microstructure, Acta Mater. 49 35653573 (2001)

10. Niu W, Bermingham MJ, Baburamani PS, Palanisamy S, Dargusch MS, Turk S, Grigson B, Sharp PK, The effect of cutting speed and heat treatment on the fatigue life of Grade 5 and Grade 23 Ti-6Al-4Valloys. Mater Des 46(4):640-644 (2013) dynamic shear deformation mechanisms have been evaluated by using the characteristics of stress-strain behaviour. By applying the compressive experimental results in reference [7], a modified J-C constitutive law is proposed for the high-temperature dynamic plastic deformation of Ti-1023 alloy.

This work is supported financially by the National Nature Science Foundation of China (Grant No. 11572337, 51575029, 11772346).

11. Su Y, He N, Li L, Li XL, An experimental investigation of effects of cooling/lubrication conditions on tool wear in high-speed end milling of Ti-6Al-4V. Wear 261(7-8):760-766 (2006)

12. Armendia M, Garay A, Iriarte LM, Arrazola PJ Comparison of the machinabilities of Ti6Al4V and TIMETAL ${ }^{\circledR}$ 54M using uncoated WC-Co tools. J Mater Process Technol 210(2):197-203 (2010)

13. Jaffery SHI, Mativenga PTWear mechanisms analysis for turning Ti-6Al-4V-towards the development of suitable tool coatings. Int J Adv Manuf Technol 58(5-8):479-493 (2012)

14. D. Bai, J. Sun, W. Chen, T. Wang, Int J Adv Manuf Technol. DOI 10.1007/s00170-016-9607-z (2016)

15. H. Yang, Z. Chen, Z. Zhou, Influence of cutting speed and tool wear on the surface integrity of the titanium alloy Ti-1023 during milling. Int J Adv Manuf Technol 78 (5-8): 1113-1126 (2015)

16. M. Long, H.J. Rack, High temperature discontinuous yielding in betaphase Ti3 Al- $(\mathrm{Nb}, \mathrm{V}, \mathrm{Mo})$ alloys, in: P.A. Blenkinsop, W.J. Evans, H.M. Flower (Eds.), Titanium'95: Science and Technology, The Institute of Materials, London, pp. 316-323 (1996)

17. M.N. Vijayshankar, S. Ankem, High temperature deformation of alpha, alpha-beta and beta titanium alloys, in: F.H. Froes, I. Caplan (Eds.), Titanium'92: Science and Technology, TMS, Warrendale, PA, pp. 1733-1739 (1993)

18. P. Wanjara, M. Jahazi, H. Monajati, S. Yue, J.-P. Immarigeon, Hot working behavior of near-alpha alloy IMI834, Mater. Sci. Eng. A 396 50-60 (2005)

19. D.G. Robertson, H.B. McShane, Isothermal hot deformation behavior of metastable $\beta$ titanium alloy Ti10V-2Fe-3AI. Mater. Sci. Technol. 13575-583 (1997) 20. V.V. Balasubrahmanyam \& Y.V.R.K. Prasad, Hot deformation mechanisms in metastable beta titanium alloy Ti-10V-2Fe-3Al, Materials Science and Technology, 171222 (2001)

21. Johnson, G.R., Cook, W.H., Fracture characteristic of three metals subjected to various strains, strain rates, temperatures and pressures. Eng. Fract. Mech. 21, 31 (1985) 